\title{
Cohort Profile: the TEMPO Cohort Study
}

Murielle Mary-Krause*1, Joel José Herranz Bustamante ${ }^{1}$, Camille Bolze ${ }^{1}$,

Cédric Galéra ${ }^{2,3,4}$, Eric J Fombonne ${ }^{5}$, Maria Melchior ${ }^{1}$

1. Sorbonne Université, INSERM, Institut Pierre Louis d'Epidémiologie et de Santé Publique (IPLESP), Equipe de Recherche en Epidémiologie Sociale (ERES), F75012, Paris, France.

2. University Hospital Unit for children and adolescents (UUHEA), CHU Bordeaux, Bordeaux, France

3. Child Psychiatry Department, Charles Perrens Hospital, Bordeaux, France

4. UMR1219, INSERM, Université de Bordeaux, Bordeaux, France

5. Departments of Psychiatry \& Pediatrics, Oregon Health \& Science University (OHSU), Portland, Oregon, USA.

\section{Corresponding author}

Murielle Mary-Krause

INSERM U1136

Faculté de Médecine St Antoine

27 rue de Chaligny

75571 Paris Cedex 12

France

murielle.mary-krause@iplesp.upmc.fr

ORCID: https://orcid.org/0000-0002-8156-1007 


\section{Key Features:}

- The main objective of the TEMPO cohort study, based throughout France, is to study risk and protective factors of trajectories of psychological difficulties or problems due to alcohol, cannabis or other illicit drugs.

- The TEMPO cohort study was set up in 1991 among 2,582 of the 4,335 initially selected at random subjects, yielding a response rate of $62.2 \%$.

- Since 1991, participants were followed-up from childhood until adulthood (over a period of 27 years), with a link to parents' longitudinal data since 1989.

- Overall, 3,401 persons participated in at least one TEMPO study wave, 2,176 at least 2 times and

1,230 at least 3 times given the opportunity to study health over time.

- Follow-up corresponds to different waves (1991, 1999, 2009, 2011, 2015 and 2018) and includes data on health, lifestyle, negative and/or positive life events, psychoactive substance consumption and socioeconomic factors.

- In 2015 study participants were invited to provide saliva samples to test for genetic risk factors of addictive behaviors ( $n=533)$.

- The majority of study participants are female (52.0\%) and have 3 years or more of post-secondary education (60.3\%). Approximately $40 \%$ of study participants have an addictive behavior, $16 \%$ had internalizing and externalizing symptoms before 17 years.

- TEMPO is a supported access resource. 


\section{Why was the cohort set up?}

In 1989, the GAZEL Cohort Study was set up to facilitate epidemiological research on various diseases and health-related factors, and to study long term adult health ${ }^{1}$. For this purpose, more than 20,000 volunteers employed by France's national utilities company (Electricité de France-Gaz de France (EDF-GDF)), aged 3550 years, were invited to participate. It is a closed occupational cohort with yearly follow-ups including health data collection on physical and mental health, psychoactive substance consumption, as well as socio-demographic, lifestyle, and occupational risk factors. The cohort is not representative of the French population, but sufficiently diverse and geographically spread to have produced rich results in many different areas of health ${ }^{2}$.

In 1991, GAZEL cohort participants who had children aged 4-18 years and resided in continental France were asked to complete a questionnaire about the development, mental health and mental health care access of one of their children. The "Children of the GAZEL cohort» study was created and all participants were followed-up in 1999. In 2009, the TEMPO (Trajectoires EpidéMiologiques en POpulation) cohort was formally established with the purpose of understanding the health problems and needs of young adults. Indeed, the period of entry into adult life is essential from a personal and professional standpoint: settling into of a stable romantic relationship, completion of formal training, labor force entry. Changes during this period can affect health in the short and long terms. The main objective of the TEMPO cohort is to study risk and protective factors of trajectories of psychological difficulties or problems due to alcohol, cannabis or other illicit drugs, particularly prevalent in this age group. Data making it possible to study other health problems, such as overweight and healthcare use, have also been collected. Moreover, the TEMPO cohort can also contribute new knowledge about associations between health and familial, social and work environments, allowing a better understanding of social inequalities in health. Because the sample's characteristics are close to those of the general population, the study was used to validate the French adaptation of the Child Behavior Checklist $(\mathrm{CBCL})^{3}$ and was included in cross-cultural comparisons in the evaluation of youth behavioral problems $\mathrm{s}^{4-8}$. The sample has also been used as a control population in a study examining whether insulin dependent diabetes mellitus affects the course of psychological adjustment in youths ${ }^{9}$.

With multiple waves of data collection since 1991, the TEMPO study is original in that participants were followed-up from childhood until adulthood (over a period of 27 years), with a link to parents' longitudinal data since 1989.

The TEMPO Cohort Study, based throughout France, is managed by the Social Epidemiology Research Group (ERES) at INSERM (French public research organization dedicated to human health)/ Sorbonne University. The TEMPO cohort received approval of bodies supervising ethical data collection in France, the Advisory Committee on the Treatment of Information for Health Research (Comité consultatif sur le 
traitement de l'information en matière de recherche dans le domaine de la santé, (CTIRS) and the French computer watchdog authority (Commission Nationale de l'Informatique et des Libertés, CNIL, $\mathrm{n}^{\circ} 908163$ ).

The TEMPO cohort is financially supported from the French National Research Agency (ANR), the French Institute for Public Health Research-IReSP (TGIR Cohortes), the French Inter-departmental Mission for the Fight against Drugs and Drug Addiction (MILDeCA), the French Institute of Cancer (INCa) and the Pfizer Foundation.

\section{Who is in the cohort? (Figure 1)}

Only one child per family was selected (at random when more than one child met eligibility criteria). Using the 1991 national census of the French population as a reference, the sample was stratified by socioeconomic status (SES) and family size with the aim of being representative of children in France in terms of family composition and socio-economic characteristics. At study inception in 1991, questionnaires accompanied by a return envelope were mailed to families by post. Data were obtained from 2,582 of the 4,335 initially selected subjects, yielding a response rate of $62.2 \%{ }^{10}$. Participants and non-participants were comparable on most socio-demographic characteristics ${ }^{11}$.

Since 1991, a total of 3,401 persons were included in TEMPO cohort and participated in at least one wave of data collection, 2,176 at least 2 times and 1,230 at least 3 times. One objective of the cohort being lifecourse trajectories estimations, among these 3,401 participants, 2,280 are eligible for tobacco consumption trajectories, 2,166 for cannabis use trajectories, 2,284 for alcohol consumption trajectories and 2,182 for alcohol abuse trajectories.

As shown in Table 1, the majority of study participants are female (52.0\%) and have 3 years or more of post-secondary education (60.3\%). Approximately $40 \%$ of study participants has an addictive behavior at some point during follow-up. Whereas in 1991 all participants resided in continental France, some have moved during the course of follow-up and live in French overseas departments or abroad. Their distribution throughout France matches the distribution of the French population ${ }^{12}$.

In comparison with the general population of young adults in France, TEMPO participants have more favorable socio-economic circumstances ${ }^{13}$

\section{How often have they been followed up? (Figure 1)}

In 1991, the 2,582 participants were identified through information about their parents available in EDFGDF human resources files. In 1999, a parental questionnaire and a youth self-administered questionnaire 
were mailed alongside information about the study and 1,268 parents (49.1\%) and 1,148 youth (44.5\%) responded.

In 2009, all participating youths were older than 18 years, and were asked directly if they wished to pursue follow-up after being informed about the study's purposes and agreeing to it. Because the researchers did not have access to participants' own address, a questionnaire was sent to all youths who had taken part in the 1991 study via their parents. Sixteen participants had died since 1991, 4 were too ill to respond and a total of 1,103 young adults aged 22 to 35 years old responded to the study questionnaire, with a response rate of $44.2 \%$, close to percentage observed in this kind of studies ${ }^{14}$.

Because of a high level of attrition, in 2011 recruitment was extended to all offspring of GAZEL study participants' aged from 18 to 35 years (one per family). Overall 1,214 participants completed the study questionnaire via a telephone interview (80\%) or online (20\%). This included 525 individuals who took part in the 2009 TEMPO study assessment and agreed to be followed-up (43.2\% participation) and 689 new participants (56.8\% participation).

In 2015, 786 people responded to the TEMPO study questionnaire (64.7\% response rate).

In 2018, all 2011 participants, aged then 25 to 44 years, were contacted; 864 responded to the study questionnaire either online (70\%) or via a postal questionnaire (30\%).

In 2020, we conducted a special wave of data collection after the COVID-19 epidemic began (8 waves of data collection between March and December 2020).

As participants were included in the TEMPO study cohort at different points in time, to describe factors associated with study participation we compare subjects included in TEMPO $(n=3,401)$ regardless of the year of inclusion, with those who were approached but did not respond (1,753 in 1991 and 2,283 in 2011) according to their parents' characteristics in 1991 (Table 2). Those who responded had parents who were more frequently married, had higher socioeconomic position (SEP), were more frequently non-smokers, and less frequently depressed.

Due to selective attrition, TEMPO cohort over-represents females, individuals with high SEP and were less likely to report tobacco smoking (Table 3$)^{15}$.

\section{What has been measured?}

The TEMPO cohort study is focused on understanding patterns of mental health and substance use, via the collection of longitudinal data (Table 4). 
In addition to the main survey, in 1991 teachers were invited to complete the CBCL Teacher's Report Form for children age 5 to $11^{5,6}(\mathrm{n}=600)$ and in 2015 study participants were invited to provide saliva samples to test for genetic risk factors of addictive behaviors ( $n=533$ ).

Parental data are available since 1989 from the GAZEL cohort data files. These include parents' age and sex, marital status, educational attainment and occupational grade, somatic and psychological problems such as depression, alcohol and tobacco use, as well as family income. Because these questions pertain to one of the parents, in 2011, questions about parents' smoking habits as well as history of psychiatric disorder were also completed by TEMPO participants using the Family Interview for Genetic Studies (FIGS) questionnaire ${ }^{16}$.

\section{What has it found?}

The TEMPO cohort follows participants since childhood, which has made it possible to study the role of early life individual and familial risk factors of mental health and addictive behaviors, as well as the impact of early behavioral and substance-related difficulties on later family and occupational standing in adulthood.

\section{Mental Health}

The effects of childhood characteristics on long-term mental health were examined in several published studies. In $2014^{17}$, we reported that frequent negative childhood events are associated with an increased likelihood of concurrent internalizing symptoms, which sometimes persist into adulthood (adjusted OddsRatio $(\mathrm{aOR})=1.51,95 \%$ confidence interval $(\mathrm{Cl})=0.42-5.41$ for one negative event, $\mathrm{aOR}=4.14,95 \% \mathrm{Cl}=1.25$ 13.76 for two negative events and $\mathrm{aOR}=8.94,95 \% \mathrm{Cl}=2.82-28.31$ for three or more negative events). Specific negative events most strongly associated with youths' persistent internalizing symptoms included school difficulties, parental stress, serious illness/health problems and social isolation. Similarly, parents' quality of relationships with their social networks was found to be associated with depression in young adulthood ${ }^{18}$. In addition, participants' own social relations early in life were shown to have consequences in terms of adult psychological well-being, as young adults who had no childhood friends were found to have higher odds of psychological difficulties including psychotic symptoms than those with at least one friend ${ }^{19,20}$. Moreover, children with internalizing symptoms are nearly 2 times more likely to experience academic failure by young adulthood than those who do not have such difficulties ${ }^{21}$. Children with externalizing problems were also found to be at risk of poor educational achievement, but this association was explained by early academic difficulties. 
Suicidal ideation and behaviors are widely prevalent among young adults (lifetime prevalence rates of suicidal ideation, plans and attempts being $47.2 \%, 14.8 \%$ and $5.7 \%$ respectively) ${ }^{22}$ and associated with job insecurity and unemployment ${ }^{23}$, which this age group is especially vulnerable to, particularly in times of economic downturn.

\section{$\underline{\text { Tobacco Smoking }}$}

Tobacco smoking is a major public health issue worldwide with substantial morbidity and mortality, tobacco being the first preventable cause of death ${ }^{24}$. Most smokers initiate tobacco use in adolescence with physical dependence and difficulty withdrawing being observed within a few months of initiation ${ }^{25}$. Individuals who initiated smoking before the age of 18 years are more likely to become daily smokers or nicotine addicts than those who began smoking in adulthood ${ }^{26}$. Individuals with high levels of childhood attention problems have higher rates of substance use (regular tobacco smoking, alcohol problems, problematic cannabis use, and lifetime cocaine use ${ }^{27}$ ). In a paper published in $2010^{28}$, we reported that, compared to offspring of non-smokers, those of persistent smokers had twofold smoking rates, while offspring of former smokers showed no excess risk. Additionally, persistent parental smoking predicts offspring heavy smoking and early smoking initiation. Overall, maternal smoking appears to be more relevant than paternal smoking. These results suggest that efforts to decrease the burden of tobacco smoking among youths may be more efficient if focused on families rather than individuals. Physicians and public health decision makers aiming to decrease the burden of tobacco smoking should take into consideration social and behavioral risk factors, such as concurrent cannabis use and financial difficulties, which are both negatively associated with successful smoking cessation ${ }^{29}$, as are job strain and symptoms of hyperactivity/inattention ${ }^{30}$.

While research shows that individual and familial factors predict adolescent smoking ${ }^{31}$, long-term smoking trajectories do not necessarily have the same determinants. Using data on tobacco use from adolescence to young adulthood, we examined early predictors of long-term smoking trajectories ${ }^{32}$. Five smoking trajectories were observed: non-smokers (62.3\%), 3 groups of persistent smokers with different levels of tobacco use (low, intermediate, high) and a group characterized by high-level smoking followed by cessation. These tobacco smoking trajectories are associated with early substance use initiation, parental smoking, and academic difficulties.

A recent study we conducted shows that factors associated with higher rates of lifetime e-cigarette use are low SEP, traditional cigarette use, and positive perceptions of e-cigarettes as well as asthma and overweight $^{33}$. Moreover, young adults who use e-cigarettes tend to persist in smoking traditional tobacco products. 


\section{$\underline{\text { Cannabis }}$}

France is one of the European countries with the highest levels of cannabis consumption, with a prevalence estimated at 22\% among 15-34 year olds ${ }^{34}$. As in other countries, cannabis is the most experimented and used illicit drug in the French population ${ }^{35}$, mainly in the form of resin and/or herbal cannabis, which is most often mixed with tobacco. We showed that there is a social gradient with regard to cannabis use, with systematically higher rates in individuals with low rather than intermediate/high SEP ${ }^{31,36}$.

There are many uncertainties regarding the direction of the association between socioeconomic characteristics and cannabis use. A study published in $2017^{37}$ shows that early cannabis initiation ( $\leq 16$ years old) predicts educational attainment even when accounting for individual and family factors. Early cannabis use and educational attainment appear more strongly associated in young women than in young men. Thus, youths who initiate cannabis use early on in life require particular attention from addiction and education specialists to reduce their odds of poor long-term outcomes.

\section{Alcohol}

Alcohol is the second cause of premature death in France and the leading cause of hospitalization ${ }^{38}$. Despite decreasing in recent years ${ }^{39}$, levels of binge drinking and alcohol intoxication in young people may have actually increased, particularly among women ${ }^{40}$. We showed that among adolescents who experienced repeated episodes of alcohol intoxication, 31\% reported alcohol abuse in young adulthood (aOR=4.27, 95\% $\mathrm{Cl}=2.21-8.27$ ) with a stronger association among participants who grew up in low SEP families ${ }^{41}$. Nevertheless, compared with participants with a stable high socioeconomic trajectory, those with an upward, downward or low socioeconomic trajectory were two to three times more likely to abstain from alcohol, indicating that alcohol use is more frequent among persons with high socioeconomic position ${ }^{42}$.

\section{What are the main strengths and weaknesses?}

The principal limitation of the TEMPO cohort is that study participants are selected. Nevertheless, even though our sample is not representative, it is more heterogeneous than the GAZEL cohort. In addition to initial characteristics related to recruitment, TEMPO is subject to attrition effects. Comparisons between participants and non-participants suggest that the dropouts were not informative since participants and non-participants did not differ on main variables. Although the sample available for analyses was slightly biased towards healthier families, the consequence is that studies are likely to provide conservative estimates of the association between predictor variables and outcomes as, for example, tobacco smoking. Therefore, the strength of observed associations may sometimes be stronger than we report. Second, some 
information is self-reported and may suffer from error, such as tobacco or cannabis initiation. Still, data in our study were collected via confidential questionnaires, which are less conducive to underreporting that in-person interviews ${ }^{43,44}$. Moreover, it is possible to cross-check the information provided across study waves. Third, as the study is based on a mailed survey, answers cannot be directly validated. However, some findings parallel those from other studies, both in terms of levels and correlates, suggesting that the data obtained are valid ${ }^{10,17,22,23,37}$. Fourth, only one parent is followed in the GAZEL cohort and some of the data on parental characteristics were incomplete. To address this limitation, we collected some information on their parents directly from TEMPO participants.

Our study has several strengths that offset the previously cited limitations. The main strength is that our data are longitudinal and collected over almost 30 years for part of the sample, which gives us the opportunity to measure changes over time. For example, we were able to evaluate shifts in psychoactive substance consumption over time and also before and after the dissemination of e-cigarettes. Second, the large sample size of this study, as well as the presence of successive birth cohorts, offers the unique possibility of examining trends over a wide range of age groups and to study different aspects of individuals' characteristics in a single study population. Third, we can take into account juvenile characteristics and negative life events, physical and psychological violence and depression assessed in childhood to search associations with different outcomes. Fourth, longitudinal measures of family and juvenile characteristics were obtained independently of participants' reports of substance use. Fifth, we can take into account several types of mental health difficulties and addictive behaviors in a single population, making it possible to study their potential associations. Sixth, a familial design with parallel data collection on parents and participating youths allows the study of the role of familial characteristics. Moreover, ascertaining parental data prospectively over 30 years through direct parental reports is more precise than informant reports used in most studies. Additionally, respondents (both parents and youths) were blind to the research hypotheses tested in studies.

\section{Can I get hold of the data?}

Anyone can submit a research project by sending an email to the principal investigator (maria.melchior@inserm.fr). If data need to be transferred, the approval of a French regulatory authority is necessary. Otherwise, the TEMPO statistical team can analyze the data in cooperation with the applicant.

Further information is available on the TEMPO website (http://www.iplesp.upmc.fr/tempo/) or from the corresponding author. 


\section{Ethics approval}

The TEMPO cohort received approval of bodies supervising ethical data collection in France, the Advisory Committee on the Treatment of Information for Health Research (Comité consultatif sur le traitement de I'information en matière de recherche dans le domaine de la santé, CCTIRS) and the French computer watchdog authority (Commission Nationale de l'Informatique et des Libertés, CNIL, nº 908163).

\section{Funding}

The TEMPO cohort is supported by the French National Research Agency (ANR), the French Institute for Public Health Research-IReSP (TGIR Cohortes), the French Inter-departmental Mission for the Fight against Drugs and Drug Addiction (MILDeCA), the French Institute of Cancer (INCa) and the Pfizer Foundation.

\section{Acknowledgements}

We thank TEMPO and GAZEL study participants who provided data for this project, as well as the GAZEL cohort study team for assistance in data collection tasks.

\section{Author contributions}

Mary-Krause $\mathrm{M}$ and Melchior $\mathrm{M}$ had the original idea for the manuscript.

Bolze $\mathrm{C}$ and Herranz Bustamante JJ were responsible for data collection and analysis.

Mary-Krause M wrote the first version of the manuscript.

Bolze C, Fombonne EJ, Galéra C, Herranz Bustamante JJ, Mary-Krause M, and Melchior M contributed to reviewing and editing manuscript.

All authors contributed to and have approved the final manuscript.

\section{Conflict of interest}

None declared 


\section{References}

1. Goldberg M, Leclerc A, Bonenfant S, et al. Cohort profile : the GAZEL Cohort Study. Int J Epidemiol 2007;36:32-39.

2. GAZEL. Vingt ans de recherche 1989-2009 [GAZEL. Twenty years of research 1989-2009]. Paris: Editions INSERM, 2009. Retrieved from http://www.gazel.inserm.fr/sites/default/files/201812/Les\%2020ans BROCHURE fr.pdf

3. Vermeersch S, Fombonne E. Le Child Behavior Checklist: Résultats préliminaires de la standardisation de la version française [The Child Behavior Checklist: Preliminary results of the French standardization]. Neuropsychiatr Enfance Adolesc 1997;45:615-620.

4. Yvanova MY, Dobrean A, Dopfner M, et al. Testing the 8-syndrome structure of the child behavior checklist in 30 societies. J clin Child Adolesc Psychol 2007;36:405-417.

5. Yvanova MY, Achenbach TM, Rescorda LA, et al. Testing the Teacher's Report Form syndromes in 20 societies. Sch Psychol Rev 2007;36:468-483.

6. Rescorla LA, Bochicchio L, Achenbach TM, et al. Parent-teacher agreement on children's problems in 21 societies. J Clin Child Adolesc Psychol 2014;43:627-642.

7. Ivanova MY, Achenbach TM, Rescorla LA, et al. Testing syndromes of psychopathology in parent and youth ratings across societies. J Clin Child Adolesc Psychol 2019;48:596-609.

8. Rescorla LA, Althoff RR, Ivanova MY, Achenbach TM. Effects of society and culture on parents' ratings of children's mental health problems in 45 societies. Eur Child Adolesc Psychiatry 2019;28:1107-1115.

9. Castro D, Tubiana-Rufi N, Moret L, Fombonne E. Psychological adjustment in a French cohort of type 1 diabetic children. PEDIAB Collaborative Group. Diabetes Metab 2000;26:29-34.

10. Galéra C, Fombonne E, Chastang JF, Bouvard M. Childhood hyperactivty-inattention symptoms and smoking in adolescence. Drug Alcohol Depend 2005;78:101-108.

11. Vermeersch S, Fombonne E. Les enfants de la cohorte GAZEL : I- Prévalence des contacts avec le système médico-éducatif pour des motifs psychologiques, et facteurs associés [Children of the GAZEL cohort: I-prevalence of contacts with the medico-educational system for psychological reasons, and associated fators]. Rev Epidemiol Sante Publique 1997;45:29-40.

12. Institut national de la statistique et des études économiques (INSEE). Estimation de population par région, sexe et grande classe d'âge - Années 1975 à 2020 [Estimated population by region, sex and large age groups - 1975 to 2010]. Retrieved from https://www.insee.fr/fr/statistiques/1893198

13. Institut national de la statistique et des études économiques (Insee). Le taux de chômage augmente au troisième trimestre [Unemployment rate rises in the third quarter]. Informations rapides Conjoncture 2011;294:1-2. Retrieved from https://www.insee.fr/fr/statistiques/1562793

14. Alonso J, Angermeyer MC, Bernert $S$, et al. Sampling and methods of the European Study of the Epidemiology of Mental Disorders (ESEMeD) project. Acta Psychiatr Scand Supp/ 2004;420:8-20.

15. Guignard R, Beck F, Richard JB, Lermenier A, Wilquin JL, Nguyen-Thanh V. La consommation de tabac en France en 2014: caractéristiques et évolutions récentes [Tobacco consumption in France in 2014: characteristics and recent trends]. Evolution 2015;31:1-10. Retrieved from http://inpes.santepubliquefrance.fr/CFESBases/catalogue/pdf/1623.pdf

16. Maxwell M. Family Interview for Genetic Studies (FIGS): a manual for FIGS. Bethesda: National Institute of Mental Health, 1992.

17. Melchior M, Touchette E, Prokofyeva E, et al. Negative events in childhood predict trajectories of internalizing symptoms up to young adulthood: an 18-year longitudinal study. PLoS One 2014;9:e114526. 
18. Allchin A, Melchior M, Fombonne E, Surkan PJ. Parental social networks during childhood and offspring depression in early adulthood: a lifecourse approach. Depress Anxiety 2016;33:1031-1038.

19. Sakyi KS, Surkan PL, Fombonne E, Chollet A, Melchior M. Childhood friendships and psychological difficulties in young adulthood: an 18 year follow-up study. Eur Child Adolesc Psychiatry 2015;24:815-826.

20. Bennett JC, Surkan PJ, Moulton LH, Fombonne E, Melchior M. Childhood social isolation and psychotic experiences in young adulthood: a community based study. Eur Child Adolesc Psychiatry 2019;Oct 8 [Epub ahead of print].

21. Zbar A, Surkan PJ, Fombonne E, Melchior M. Early emotional and behavioral difficulties and adult educational attainment: an 18-year follow-up of the TEMPO study. Eur Child Adolesc Psychiatry 2016;25:1141-1143.

22. Fedorowicz VJ, Fombonne E. Suicidal behaviours in a population-based sample of French youth. Can J Psychiatry 2007;52:772-779.

23. Dalglish SL, Melchior M, Younes N, Surkan PJ. Work characteristics and suicidal ideation in young adults in France. Soc Psychiatry Psychiatr Epidemiol 2015;50:613-620.

24. Peacock A, Leung J, Larney S, et al. Global statistics on alcohol, tobacco and illicit drug use: 2017 status report. Addiction 2018;113:1905-1926.

25. Kandel DB, Logan JA. Patterns of drug use from adolescence to young adulthood: I. Periods of risk for initiation, continued use, and discontinuation. Am J Public Health 1984;74:660-666.

26. Myers MG, Brown SA. Smoking and health in substance abusing adolescence: a 2 year follow-up. Pediatrics 1994;93:561-566.

27. Galéra C, Pingault JB, Fombonne E, et al. Attention problems in childhood and adult substance use. J Pediatr 2013;163:1677-1683.

28. Melchior M, Chastang J-F, Mackinnon D, Galéra C, Fombonne E. The intergenerational transmission of tobacco smoking--the role of parents' long-term smoking trajectories. Drug Alcohol Depend 2010;107:257-60.

29. Bowes L, Chollet A, Fombonne E, Melchior M. Phychological, social and familial factors associated with tobacco cessation among young adults. Eur Addict Res 2015;21:153-159.

30. Khati I, Menvielle G, Chollet A, Younès N, Metadieu B, Melchior M. What distinguishes successful from unsuccessful tobacco smoking cessation? Data from a study of young adults (TEMPO). Prev Med Rep 2015;2:679-685.

31. Bowes L, Chollet A, Fombonne E, Galéra C, Melchior M. Lifecourse SEP and tobacco and cannabis use. Eur J Public Health 2013;23:322-327.

32. Clergue-Duval V, Mary-Krause M, Bolze C, Fombonne E, Melchior M. Early predictors of trajectories of tobacco use level from adolescence to young adulthood: A 16-year follow-up of the TEMPO cohort study (1999-2015). Eur Addict Res 2019;25:2-9.

33. Aljandaleh H, Bolze C, El-Khoury Lesueur F, Melchior M, Mary-Krause M. Factors associated with electronic cigarette use among young adults: The French «Trajectoires EpidéMiologiques en Population » (TEMPO) Cohort study. Subst Use Misuse 2020;Jan 30:1-9.

34. European Monitoring Centre for Drugs and Drug Addiction. European Drug Report 2019: trends and developments. Luxembourg: Publications Office of the European Union, 2019. Retrieved from http://www.emcdda.europa.eu/system/files/publications/11364/20191724 TDAT19001ENN PDF. pdf

35. Beck F, Spilka S, Nguyen-Thanh Viêt, Gautier A, Le Nézet O, Richard JB. Cannabis : Usages actuels en population adulte: Résultats de l'enquête Baromètre santé 2016 [Cannabis: Current uses among 
adults. Results from the 2016 wave of the French Health Barometer]. Tendances 2017, 119: 1-4. Retrieved from https://www.ofdt.fr/BDD/publications/docs/eftxfbx6.pdf

36. Redonnet B, Chollet A, Fombonne E, Bowes L, Melchior M. Tobacco, alcohol, cannabis and other illegal drug use among young adults: the socioeconomic context. Drug Alcohol Depend 2012;121:231-239.

37. Melchior M, Bolze C, Fombonne E, Surkan PJ, Pryor L, Jauffret-Roustide M. Early cannabis initiation and educational attainment: is the association causal? Data from the French TEMPO study. Int J Epidemiol 2017;46:1641-1650.

38. Naassila M, Nalpas B. Alcool et Santé. Lutter contre un fardeau à multiples facettes [Alcohol and health. Addressing a multifaceted burden]. INSERM, Dossiers d'information. Paris: Editions INSERM, 2016. Retrieved from https://www.inserm.fr/information-en-sante/dossiers-information/alcoolsante

39. Spilka $S$, Le Nézet $O$, Janssen $E$, et al. les drogues à 17 ans: Analyse de l'enquête ESCAPAD 2017 [Drugs at 17: 2017 ESCAPAD Survey analysis]. Tendances 2018;123:1-8. Retrieved from https://www.ofdt.fr/BDD/publications/docs/eftxssy2.pdf

40. Beck F, Richard JB, Guignard R, Le Nézet O, Spilka S. Les niveaux d'usage des drogues en France en 2014 [Levels of drug use in France in 2014]. Tendances 2015;99:1-8. Retrieved from https://www.ofdt.fr/BDD/publications/docs/eftxfbv3.pdf

41. Yaogo A, Fombonne E, Lert F, Melchior M. Adolescent repeated alcohol intoxication as a predictor of young aldulthood alcohol abuse: the role of socioeconomic context. Subst Use Misuse 2015;50:1795-1804.

42. Yaogo A, Fombonne E, Kouanda S, Lert F, Melchior M. Lifecourse socioeconomic position and alcohol use in young adulthood: Results from the French TEMPO Cohort Study. Alcohol Alcohol 2014;49:109-116.

43. Mayet A, Esvan M, Marimoutou C, et al. the accuracy of self-reported data concerning recent cannabis use in the French armed forces. Eur J Public Health 2013;23:328-332.

44. Moskowitz JM. Assessement of cigarette smoking and smoking susceptibility among youth. Telephone computer-assisted self-interviews versus computer-assisted telephone interviews. Public Opin Q 2004;68:565-587.

45. Melchior M, Caspi A, Milne BJ, Danese A, Poulton R, Moffitt YE. Work stress precipitates depression and anxiety in young, working women and men. Psychol Med 2007;37(8) :1119-1129.

46. Family Interview for Genetic Studies (FIGS). Retrieved from https://www.nimhgenetics.org/resources/clinical-instruments/figs/overview

47. Karasek RA. Job demands, job decision latitude, and mental strain: implications for job redesign. Adm Sci Q 1979;24:285-308.

48. Beck F, Cavalin C, Maillochon F. Violences et santé en France. Etat des lieux [Violence and health in France. Situation]. Paris: Direction de l'information légale et administrative, 2010. Retrieved from https://drees.solidarites-sante.gouv.fr/IMG/pdf/violence sante 2010.pdf

49. Bukowski WM, Hoza B, Boivin M. Measuring friendship quality during pre- and early adolescence: the development and psychometric properties of the friendship qualities scale. J Soc Pers Relat 1994; 11:471-484.

50. Melchior M, Berkman LF, Niedhammer I, Chea M, Goldberg M. Social relations and self-reported health: a prospective analysis of the French GAZEL cohort. Soc Sci Med 2003;56:1817-1830.

51. Buss A, Plomin R. Temperament: Early developing personality traits. London: Lawrence Erlbaum Associates, 1984. 
52. Gasman I, Purper-Ouakil D, Michel G, et al. Cross-cultural assessment of childhood temperament. A confirmatory factor analysis of the French Emotionality Activity and Sociablity (EAS) questionnaire. Europ Child Adolesc Psychiatry 2002;11:101-107.

53. Rammstedt B, John OP. Measuring personality in one minute or less: A 10-item short version of the Big Five Inventory in English and German. J Res Personality 2007;41:203-2012.

54. American Psychiatric Association. Diagnostic and statistical manual of mental disorders (DSM-5). Arlington: American Psychiatric Publishing, 5th edition, 2013.

55. Achenbach TM. Manual for the Child Behavior Checklist/4-18 and 1991 profile. Burlington: University of Vermont, 1991.

56. Teacher's Report Form for ages 6-18. Retrieved from https://aseba.org/wpcontent/uploads/2019/02/trf.pdf

57. Achenbach TM, Becker A, Döpfner M, et al. Multicultural assessment of child and adolescent psychopathology with ASEBA and SDQ instruments: research findings, applications, and future directions. J Child Psychol Psychiatry 2008;49:251-275.

58. Adult Self Report for ages 18-59. Retrieved from https://aseba.org/wpcontent/uploads/2019/02/asr.pdf

59. Sheehan DV, Lecrubier Y, Sheehan KH, et al. The Mini-International Neuropsychiatric Interview (M.I.N.I.): the development and validation of a structured diagnostic psychiatric interview for DSMIV and ICD-10. J Clin Psychiatry 1998; 59 (Suppl20):22-33, quiz 34-57.

60. Johnston LD, O'Malley PM, Bachman JG. National survey results on drug use from the Monitoring the Future Study, 1975-1994. Rockville: National Institute on Drug Abuse, 1995.

61. Aron A, Aron A. Tips for SPS researcher (Revised November 21, 2013). Retrieved from http://hsperson.com/pdf/Tips for SPS Researchers Nov21 2013.pdf

62. Heatherton TF, Kozlowski LT, Frecker RC, Fagerstrom KO. The Fagerstrom Test for Nicotine Dependence : a revision of the Fagerstrom Tolerance Questionnaire. Br J Addict 1991;86:11191127.

63. Babor TF, Higgins-Biddle JC, Saunders JB, Monteiro MG. AUDIT: the Alcohol Use Disorders Identification Test: guidelines for use in primary health care. Geneva: Word Health Organization, $2^{\text {nd }}$ Edition, 2007.

64. Legleye S, Kraus L, Piontek D, Phan O, Jouanne C. Validation of the Cannabis Abuse Screening Test in a sample of cannabis inpatients. Eur Addict Res 2012; 18(4):193-200 